\title{
SUCCESSION FOLLOWING THE 1974 WATERFALLS CANYON FIRE AND OTHER RECENT FIRES IN Grand Teton National PaRk
}

\author{
KATHLEEN M. DOYLE $\downarrow$ DENNIS H. KNIGHT \\ DEPARTMENT OF BOTANY UNIVERSITY OF WYOMING \\ LARAMIE
}

The focus of our research is to understand the rates and patterns of vegetation succession following fires in Grand Teton National Park. Our approach combines an intensive long-term study of biotic change on individual sites in Waterfalls Canyon, with an extensive investigation of the spatial variability of succession following fire throughout Grand Teton National Park.

Our 1992 proposal outlined two broad objectives. First, we proposed to resurvey permanent plots at four study sites in Waterfalls Canyon for vegetation and bird abundance using the methods established by Barmore et al. (1976) and to summarize all the vegetation, bird and small mammal data which were collected from these permanent plots between 1975 and 1992. Our second major objective is to analyze the variability in plant establishment patterns and environmental conditions on six recent burns in the Teton region. The goal of our analysis is to demonstrate correspondence between vegetation patterns and the environmental variables that we measure. We feel that combining these two approaches to studying succession, namely a long term site-specific approach and a short term but spatially extensive approach will enable us to develop a model for predicting successional trends following fire within Grand Teton National Park.

In the following paragraphs we outline the work that we have completed to date, the work that we are currently undertaking, and finally, a synopsis of the work we plan to complete before the end of this cooperative agreement.

\section{$\checkmark \quad$ ACCOMPLISHMENTS TO DATE}

Objective 1. Waterfalls Canyon Permanent Plot Study

Bird Data

Data on breeding bird density were collected during June and July, 1992, in conjunction with Rick Wallen, Grand Teton Park Biologist, at each of the 4 study sites in Waterfalls Canyon (old growth, 1932 burn, 1974 severe burn and 1974 moderate burn). Methods established by Barmore et al. (1976) were followed. In addition, data on habitat characteristics were collected for each sampling point on the four bird survey transects. All of the breeding bird density data, including that collected in 1975,1976 , 1977 and 1983 by Barmore et al. (1976), have been entered into a computer file using LOTUS 1-2-3 software.

\section{Vegetation Data}

In July, 1991, we relocated and sampled the vegetation in each of three $15 \times 25 \mathrm{~m}$ macroplots at the four permanent plot locations, following the methods utilized in past vegetation sampling at these sites by Barmore et al. (1976). Voucher specimens were collected for many of the plant species found. We have entered understory and overstory data for all years (1975 - 1991) into a computer file using 
LOTUS 1-2-3 software. During the summer of 1992, each of the macroplots was revisited and photographs were taken from photo points established by Barmore et al. (1976) to document changes in vegetation. Data on the environmental characteristics of each of these plots such as slope, aspect, and soil characteristics were also collected in 1992.

\section{Small Mammal Data}

Based on our analysis of the small mammal data collected between 1975 and 1992 at the Waterfalls Canyon permanent plots, we concluded that inconsistencies in the method of data collection, combined with ongoing and more detailed research being conducted by Nancy Stanton and David Spildie on the response of small mammals to fire, suggested that our time would not be well spent resampling small mammals in 1992. To date, all of the small mammal data from 1975 - 1983 has been entered into a computer file using LOTUS 1-2-3 software and has been summarized. A report on the problems associated with the small mammal data was submitted along with our continuation proposal.

Objective 2. Spatial Variability of Succession Following Fire

Collection of Data and Refinement of Methods

During the summer of 1992 (May through August) a total of 37 stands were sampled within 6 recent fires in or adjacent to Grand Teton National Park. These fires include the 1974 Waterfalls Canyon Fire, the 1981 Mystic Isle Fire, the 1985 Beaver Creek Fire, the 1987 Dave Adams Hill Fire, the 1988 Hunter Fire, and the 1988 Huck Fire. Using aerial photographs, geology, soils and topographic maps and on-site reconnaissance, stands were selected to represent the variability in biotic and abiotic conditions within the burn as a whole. Within each stand data were collected from one, two or three $(5 \times 30 \mathrm{~m})$ plots, depending on the size of the stand. Data were collected on the percent cover of herbaceous plants and woody shrubs and the density of seedlings, saplings and mature trees (dead and alive) within each $5 \times 30 \mathrm{~m}$ plot. Other variables that we measured or estimated were slope, aspect, elevation, fire intensity, distance to unburned forest, ridgetop and valley bottom. In addition soil horizons were described and soil texture was estimated to a depth of ca $50 \mathrm{~cm}$. Soil samples were collected from each plot for future analysis.

\section{WORK IN PROGRESS}

Objective 1. Waterfalls Canyon Permanent Plot
Study Data Summary and Preparation of Final Report

We are currently identifying all of the unknown plant specimens collected within the permanent plots in Waterfalls Canyon. When this task is completed, the computerized data will be updated accordingly and data from all years will be summarized in a tabular format. We expect that a written report of our results for the Waterfalls Canyon Permanent Plot study will be completed by the spring of 1993. We plan to present our results at the annual meeting of the Ecological Society of America and submit a manuscript to a peer-reviewed journal.

Objective 2. Spatial Variability of Succession Following Fire

\section{Development of GIS Database}

The development of a prototype GIS database using GRASS is underway for the Dave Adams Hill Fire. This database will consist of slope, aspect, elevation, geologic substrate and fire patch boundaries derived from aerial photos. We are coordinating our efforts with Sue Fullerton, GIS specialist at Grand Teton National Park, in order to develop a database which will meet our research needs. Our preliminary use of this database will be to classify the landscape and stratify our sampling locations within each of the fires according to the landscape classes we derive. This database will also be useful in analyzing our data in a spatially explicit manner.

\section{Analysis of 1992 Data}

The identification of plant specimens, the analysis of soil samples, data entry, and analysis of data collected in 1992 will be started in late spring 1993 and continue through December. 
Refine Methods and Preparation of 1993 Continuation Proposal

During the spring of 1993 and early summer 1993 we will concentrate on the further development and identification of the techniques we will use to treat and analyze our data. Progress on this objective will be reported in our 1993 continuation proposal.

\section{$\checkmark$ RESEARCH SCHEDULE}

Spring - Summer 1993: Prepare continuation proposal. Complete Final Report on results of the Waterfalls Canyon permanent plot study and submit to peer-reviewed journal. Present results at ESA annual meeting. Continue the development of a GIS database. Make progress regarding how data will be treated and analyzed. Start entry of 1992 data and conduct preliminary analysis. Continue with data collection in Grand Teton National Park.

Fall 1993: Continue with data analysis and development of successional model.

Spring 1994: Continue with data analysis and model development. Seek funding for continuation of project for one additional year.

Summer 1994: Sample additional stands within the six burns identified.

Fall 1994 - Summer 1995: Complete data analysis and write dissertation.

In summary, field work and data analysis are on schedule. We feel that the kind of research we are undertaking has important applications for natural resource managers. Succession during the first twenty years following a stand-replacing fire is likely to shape the vegetation patterns on that site for decades to come. Thus, knowledge about successional trends has implications for understanding available habitat for wildlife, patterns of biological diversity, and ecosystem processes at various scales.
Furthermore, we believe our research has potential significance beyond Grand Teton National Park and the Greater Yellowstone Region. Very little quantitative research has been conducted to understand relationships between successional patterns and environmental variables in the Rocky Mountains. In addition, techniques developed through this research may provide a model for studying the spatial heterogeneity of secondary succession in other landscapes.

\section{$\checkmark \quad$ LITERATURE CITED}

Barmore, W. J., D. L. Taylor, and P. Hayden. 1976. Ecological effects and biotic succession following the 1974 Waterfalls Canyon fire in Grand Teton National Park. Unpublished report, GTNP. 